\title{
Methods of data analysis for the ball cratering test on TiN and DLC coated steel
}

\author{
W. M. Silva ${ }^{a *, \text { P. S. Souza }}{ }^{b}$ and J. R. Carneiro ${ }^{b}$ \\ ${ }^{a}$ Department of Rural Engineering, São Paulo State University - UNESP, Rua José Barbosa de Barros, \\ $n^{\circ}$ 1780, CEP 18610-307, Botucatu, SP, Brazil \\ ${ }^{b}$ Department of Mechanical Engineering, Pontifical Catholic University of Minas Gerais - PUC Minas, \\ Av. Dom José Gaspar n 500, CEP 30535-610, Belo Horizonte MG, Brazil
}

Received: January 22, 2015; Revised: September 18, 2015; Accepted: November 17, 2015

Titanium nitride (TiN) coatings are widely used in machining because of its mechanical characteristics which modify the surface of the substrate increasing the capacity of load support and reduction of friction, while a coating as diamond-like carbon (DLC), which also has interesting mechanical properties, needs better attention. In this sense, the development of new coatings such as DLC is as important as wear analysis techniques. This work discusses the methods available to assess abrasive wear of coatings. For this, it has been used the data of the crater volume formed in ball cratering test and compared the difference between the specific wear coefficients of substrate and coating (ks and kc). These coefficients depend of the methods used for data analyses, thus, it has been used four equations to calculate ks and kc. Moreover, profilometry (pf) has been used to calculate the volumes, and thus $\mathrm{ks}$ and $\mathrm{kc}$. Also, the roughness of the coatings, the thickness, the images corresponding to the crater formed, the coefficient of friction, the data obtained in wear tests due to the volume removed and, in the end, a comparison between ks and kc by different methods of data analyzes are presented.

Keywords: Coating, TiN, Diamond-like carbon, Wear, Ball cratering.

\section{Introduction}

Cutting tools with titanium nitride ( $\mathrm{TiN}$ ) coating are widely used due its mechanical properties such as high wear resistance and low friction. A new and promising coating for the same application is diamond-like carbon (DLC). One of the primary functions is to improve the wear resistance and thus increase the durability of components and products for engineering coatings such as TiN and DLC. Robust wear testing techniques are required to determine those aspects of the coatings performance ${ }^{1}$, and most of them are based on friction and wear ${ }^{2-5}$. Often, the test parameters involved depend of: the tribo system properties, the materials in contact, the surrounding and wear conditions ${ }^{6}$. There are few successful methods of wear test, for example: ball bearing, pin on disk and ball on disk. Nevertheless, those techniques are common, new approaches of data analyses are being raised by tribologists.

Considerable progress has been made in the last decade with the development of the ball cratering test ${ }^{7}$. In this test, a ball is rotated and pressed against the coated test sample. Abrasive slurry is introduced between the ball and the test sample. After a fixed number of revolutions, the volume of the crater formed is used to calculate the wear. Advantages of this test are: the operation simplicity, the low cost of the apparatus and the small scale of the samples. Moreover, ball cratering test method can be used to evaluate a variety of coating including polymeric films, thin hard ceramic coatings, metallic coatings and thick

*e-mail: williammelosilva@gmail.com thermally sprayed coatings ${ }^{8}$. Alternative ball cratering test was proposed by Gee and Wicks ${ }^{9}$. They used a test system which enables sliding wear and friction test of TiN and DLC coatings without the presence of added abrasive.

Bearing steel ball produces a circular depression which is used to determine the wear rate of the coating and the substrate. The wear is confined to the coating alone and a wear rate is calculated by geometrical considerations. Next, a sequence of craters with different duration penetrates the coating, producing two boundaries on overall crater diameter and the portion of the crater in the substrate. Dimensional analysis of these features results in wear rates for both the substrate and the coating. A disadvantage is the reliability of ball cratering test which is related to the measurement accuracy. Thus, optical microscopy has become a conventional tool for measuring the diameter of the wear crater generated in the abrasion test, and a primary method of measurement. Profilometer (Pf) for ancillary measurements in order to evaluate the crater has been proposed in this work as alternative technique for analysis.

This paper discusses the methods to evaluate the shape of the crater formed in the ball cratering test and the influence of the accuracy in the specific wear rate of TiN and DLC coatings. The sets of coatings tested here were useful to provide information on the wear and friction performance of the DLC, giving guidance in the application of this coating in sliding wear applications, since TiN is widely known. 


\section{Material and Methods}

\subsection{Experimental set-up and coating characterization}

Two sets of coatings have been tested: titanium nitride (TiN) coating, which is widely used in the machining factories, and DLC which is a new and promising coating. For both coatings, it has been used M2 steel substrates. DC plasma in physical vapor deposition (PVD) system has been utilized to synthesize TiN coating, and vacuum arc discharge PVD with graphite cathode was used for DLC.

The ball cratering test conditions were AISI 52100 steel ball of $15 \mathrm{~mm}$ radius, constant velocity of $0.1 \mathrm{~m} / \mathrm{s}$, load of $0.3 \mathrm{~N}$, diamond paste $(3 \mu \mathrm{m})$ and silica solution $20 \%$ diluted in ethylene glycol. The crater images were taken by optical microscope for measuring the shape of the crater in the conventional method. Alternative for measuring the crater was performed in $3 \mathrm{D}$ profilometer equipment Taylor-Robson, software TalyMap Universal. Images were carried out with fixed sample and the probe displacement with a resolution of $65 \mathrm{~nm}$ in z-axis, $250 \mathrm{~nm}$ and $1000 \mathrm{~nm}$ in $\mathrm{x}, \mathrm{y}$-axis. The results obtained by using the conventional method were useful as reference for the evaluation and comparison with the profilometry technique. Images of the coating thickness were obtained using scanning electron microscopy (SEM), Hitachi S-3400 VP. Top view of the coating morphology was evaluated by atomic force microscopy (AFM) Veeco multimode Nanoscope V. AFM technique was also used to obtain the roughness by the $\mathrm{Ra}$ - factor, based on the relation: $R_{a}=\frac{1}{l} \int_{0}^{l} f(x) d x$, where $l$ is the sampling length of the profile and $f(x)$ is the functional form of the profile heights measured from a reference line.

\subsection{Data analyses methods of the ball cratering test}

The ball cratering wear test is illustrated in Figure 1. Figure 1 shows a test illustration with a schematic diagram of the geometry of wear scars formed by ball cratering test with a sphere of radius $\mathrm{R}$, internal crater diameter a, external crater diameter $b$, coating thickness $t$ and the total penetration depth $\mathrm{h}$ into the sample. In this test, experimental data are provided by the analyses of the craters made for a predetermined number of ball cycle, then wear rates for both the substrate and the coating can be derived ${ }^{10}$.

The wear volume was calculated by a model for abrasive wear $^{11}$ which is equivalent to the Archard equation:

$\mathrm{S} . \mathrm{N}=\frac{\mathrm{V}}{\mathrm{k}}$

Where $\mathrm{k}$ is the specific wear rate or wear coefficient, $\mathrm{V}$ is the volume, $\mathrm{S}$ is the sliding distance and $\mathrm{N}$, the normal load.

We are assuming the expression (2) to calculate k:

$\frac{\mathrm{V}}{\mathrm{S}}=\mathrm{k} \cdot \mathrm{N} \rightarrow \frac{\mathrm{S} \cdot \mathrm{N}}{\mathrm{V}}=\frac{1}{\mathrm{k}}$

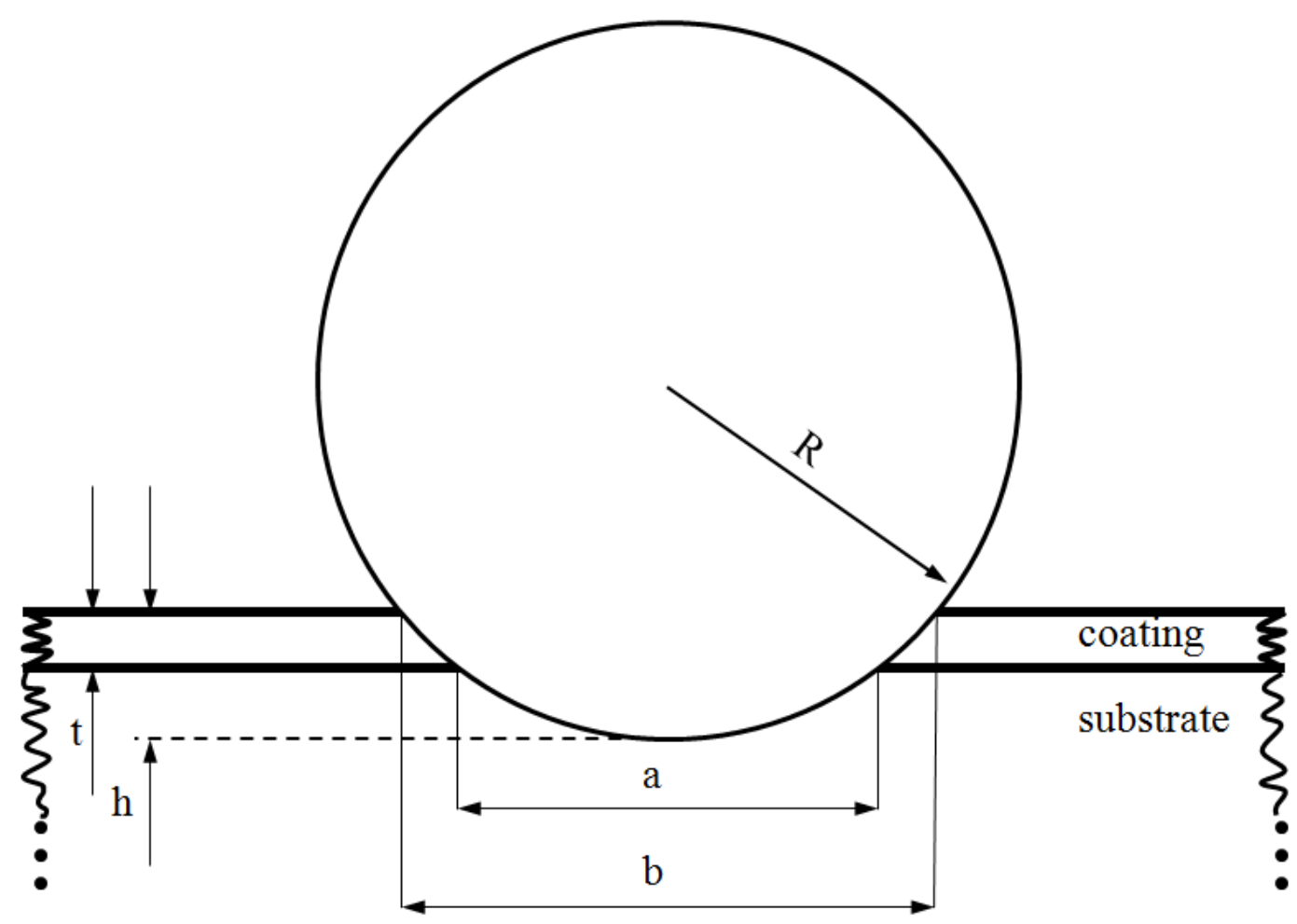

Figure 1. Schematic diagram showing the geometry of wear scars formed by micro-scale abrasion testing with a sphere of radius R in a coated sample. 
Linear plot of $\mathrm{SN} / \mathrm{V}_{\mathrm{c}}$ versus $\mathrm{V}_{\mathrm{s}} / \mathrm{V}_{\mathrm{c}}$ was used to obtain the wear coefficient of the coating $\left(\mathrm{k}_{\mathrm{c}}\right)$ and substrate $\left(\mathrm{k}_{\mathrm{s}}\right)$ as shown in Figure 2. Thus, an equation (3) can be obtained by

$$
\frac{\mathrm{S} . \mathrm{N}}{\mathrm{V}_{\mathrm{c}}}=\frac{1}{\mathrm{k}_{\mathrm{s}}} \frac{\mathrm{V}_{\mathrm{s}}}{\mathrm{V}_{\mathrm{c}}}+\frac{1}{\mathrm{k}_{\mathrm{c}}}
$$

where $\mathrm{V}_{\mathrm{c}}$ and $\mathrm{V}_{\mathrm{s}}$ are the volumes of coating and substrate, respectively ${ }^{12}$.

The thickness must be obtained via an independent method to ensure accuracy, thus avoiding the propagation of systematic errors in the final result. The volumes of coating and substrate were calculated by (4) and (5) ${ }^{13}$ :

$\mathrm{V}_{\mathrm{s}}=\frac{\pi \mathrm{a}^{4}}{64 \mathrm{R}}$

$\mathrm{V}_{\mathrm{c}}=\frac{\pi \mathrm{t}}{4}\left(\mathrm{a}^{2}+4 \mathrm{Rt}\right)$

The symmetrical formulation also allows both specific wear rates from a single test and a linear plot. For coated substrate, where each component is assumed to have its own specific wear rate, a combined wear equation (6) is given by:

$\mathrm{S} . \mathrm{N}=\frac{\mathrm{V}_{\mathrm{c}}}{\mathrm{k}_{\mathrm{c}}}+\frac{\mathrm{V}_{\mathrm{s}}}{\mathrm{k}_{\mathrm{s}}}$

Rearrangement of equation 2 can produce two equations to calculate $\mathrm{k}_{\mathrm{s}}$ and $\mathrm{k}_{\mathrm{c}}$ :

$\mathrm{k}_{\mathrm{s}}=\frac{\mathrm{V}_{\mathrm{s}}}{\mathrm{S} \cdot \mathrm{N}_{\mathrm{s}}}$

$\mathrm{k}_{\mathrm{c}}=\frac{\mathrm{V}_{\mathrm{c}}}{\mathrm{S} \cdot \mathrm{N}_{\mathrm{c}}}$

To estimate the wear coefficient of the material, Rutherford and Hutchings ${ }^{14}$ proposed that the volume $\mathrm{V}$ varies with distance $\mathrm{S}$, and this is directly proportional by constant $\mathrm{k}$ and a normal force applied $\mathrm{N}$ according to the relation (9):

$\frac{\mathrm{dV}}{\mathrm{dS}}=\mathrm{kN}$

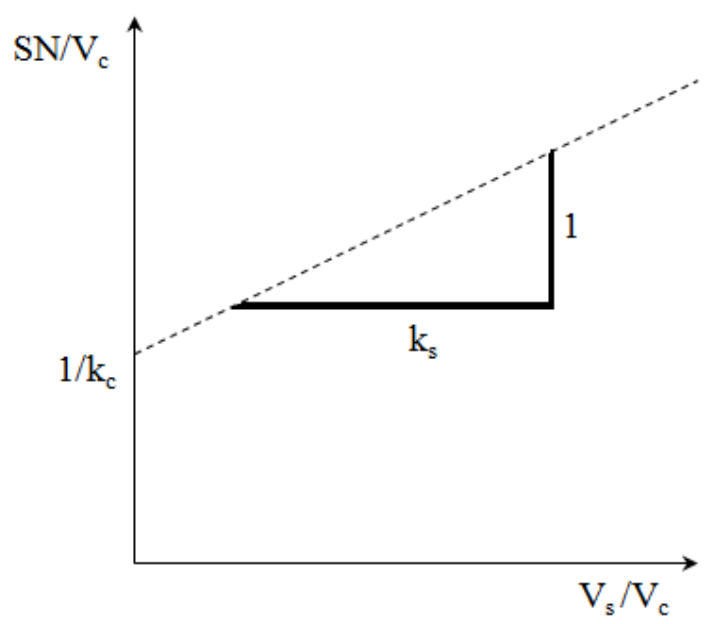

Figure 2. Schematic diagram showing linear plot obtained by plotting S.N/Vc against Vs/Vc.
The wear equation (9) can be shown to be equivalent:

$\frac{\mathrm{dV}}{\mathrm{dS}}=\frac{\mathrm{dV}_{\mathrm{c}}}{\mathrm{dS}}+\frac{\mathrm{dV}_{\mathrm{s}}}{\mathrm{dS}}=\mathrm{k}_{\mathrm{c}} \mathrm{N}_{\mathrm{c}}+\mathrm{k}_{\mathrm{s}} \mathrm{N}_{\mathrm{s}}$

where:

$\frac{\mathrm{dV}_{\mathrm{c}}}{\mathrm{dS}}=\mathrm{k}_{\mathrm{c}} \mathrm{N}_{\mathrm{c}}$

and

$\frac{\mathrm{dV}_{\mathrm{s}}}{\mathrm{dS}}=\mathrm{k}_{\mathrm{S}} \mathrm{N}_{\mathrm{s}}$

Assuming that the specific wear rates are constant, integration of these two equations gives (13) and (14):

$\frac{\mathrm{V}_{\mathrm{c}}}{\mathrm{k}_{\mathrm{c}}}=\int \mathrm{N}_{\mathrm{c}} \mathrm{dS}$

and

$\frac{\mathrm{V}_{\mathrm{S}}}{\mathrm{k}_{\mathrm{S}}}=\int \mathrm{N}_{\mathrm{s}} \mathrm{dS}$

therefore

$\frac{\mathrm{V}_{\mathrm{c}}}{\mathrm{k}_{\mathrm{c}}}+\frac{\mathrm{V}_{\mathrm{s}}}{\mathrm{k}_{\mathrm{s}}}=\int\left(\mathrm{N}_{\mathrm{c}}+\mathrm{N}_{\mathrm{s}}\right) \mathrm{dS}=\int \mathrm{NdS}=\mathrm{S} . \mathrm{N}$

According to Kusano et al. (2004), data analyses cannot be interpreted by just a single method, a use of the wrong method can lead to poor accuracy in the resulting specific wear rates. To avoid this, four equations have been compared and used to the experimental data obtained. They are labeled as AT, Vs-AT, Vc-AT and DI. 'AT' method is the Rutherford formulation, using the inner crater diameter a and independently measured coating thickness t. 'Vs-AT' and 'Vc-AT' method are the Allsopp formulation using the inner crater diameter a and the independently measured coating thickness. 'Double intercept - DI' method is the formulation which uses the inner diameter a and the predetermined coating thickness $\mathrm{t}^{10}$. The equations related to 'AT', 'Vs-AT', 'Vc-AT' and DI are described in the Table 1.

\section{Results and discussion}

The tools covered with TiN normally have $4 \mu \mathrm{m}$ thickness, as well the samples used here and shown in the cross section-view evaluated by SEM in Figure 3. In

Table 1 - Data analysis methods.

\begin{tabular}{cc}
\hline Method & Equation \\
\hline AT & $\frac{\mathrm{SN}}{\mathrm{V}}=\left(\frac{1}{\mathrm{k}_{\mathrm{c}}}-\frac{1}{\mathrm{k}_{\mathrm{s}}}\right) \frac{\mathrm{V}_{\mathrm{s}}}{\mathrm{V}}+\frac{1}{\mathrm{k}_{\mathrm{s}}}$ \\
Vs-AT & $\frac{\mathrm{SN}}{\mathrm{V}_{\mathrm{s}}}=\frac{1}{\mathrm{k}_{\mathrm{c}}} \frac{\mathrm{V}_{\mathrm{c}}}{\mathrm{V}_{\mathrm{s}}}+\frac{1}{\mathrm{k}_{\mathrm{s}}}$ \\
Vc-AT & $\frac{1}{\mathrm{k}_{\mathrm{s}}} \frac{\mathrm{V}_{\mathrm{s}}}{\mathrm{V}_{\mathrm{c}}}+\frac{1}{\mathrm{k}_{\mathrm{c}}}$ \\
DI & $\frac{1}{\mathrm{k}_{\mathrm{s}}} \frac{\mathrm{V}_{\mathrm{S}}}{\mathrm{SN}}+\frac{1}{\mathrm{k}_{\mathrm{c}}} \frac{\mathrm{V}_{\mathrm{c}}}{\mathrm{SN}}=1$ \\
\hline
\end{tabular}




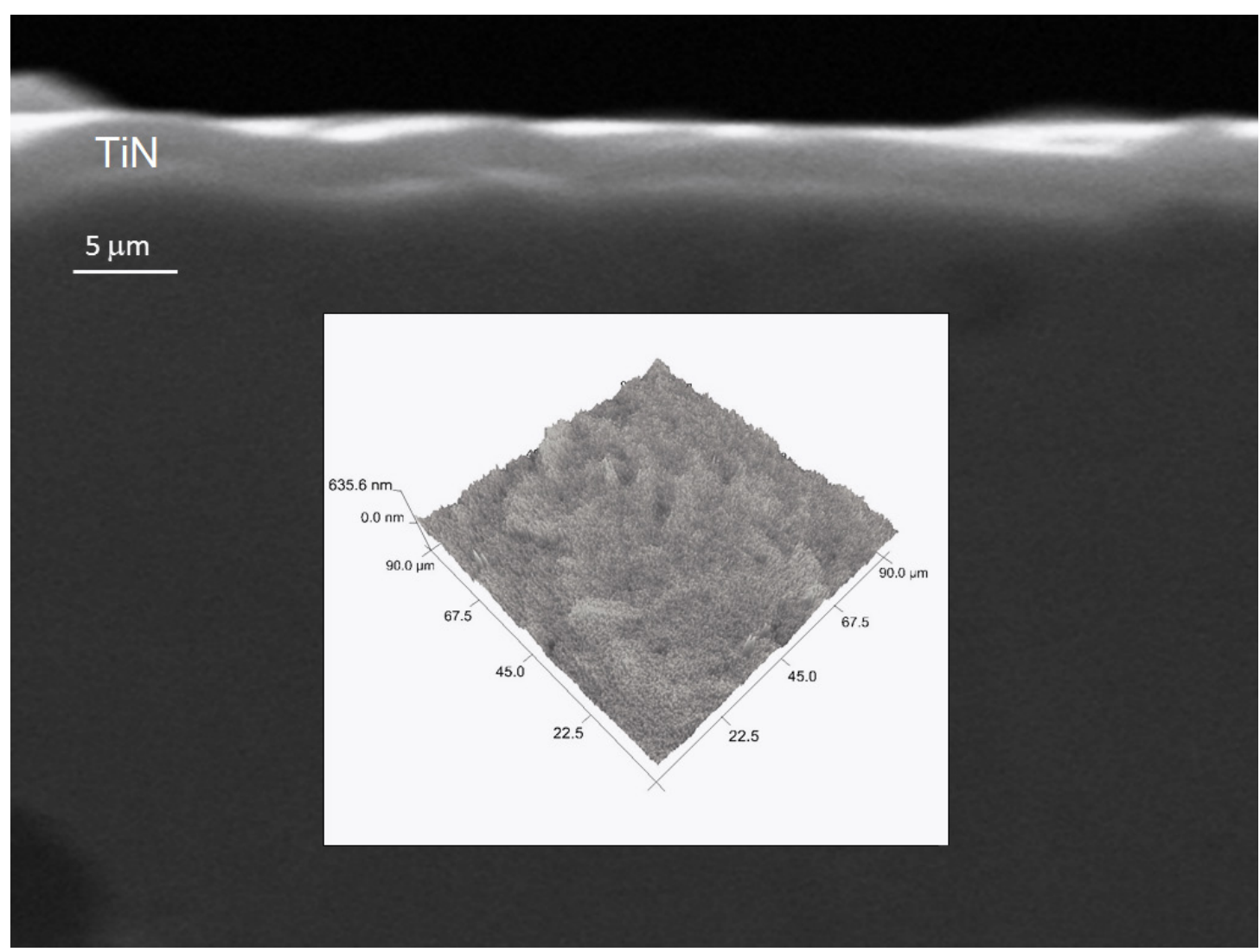

Figure 3. Cross-section view of the thickness of TiN coating by scanning electron microscopy and the morphology of the TiN coating by AFM (inside).

this same Figure, the TiN coating morphology by AFM is presented inside, the TiN roughness obtained by AFM is $90 \mathrm{~nm}$. As expected, the roughness of the TiN deposited by PVD system was low and follows the shape of the substrate, indicating that the coating has satisfactory adhesion. In the other hand, DLC is a new technology and needs better attention due adhesion issues that limits its use ${ }^{15,16}$, although is an interesting type of coating because of its high hardness and chemical inertness ${ }^{17}$. The DLC with $1 \mu \mathrm{m}$ thickness shows satisfactory adhesion, and the interface between coating and substrate is clear, as shown in Figure 4. Also, the morphology of DLC is homogeneous and the roughness calculated is $62 \mathrm{~nm}$. Despite the DLC roughness is lower than TiN, other mechanical properties may influence the wear results and discussed forward, apparently, the slight difference of roughness do not interfere significantly on the wear.

It is known that when perforation of the coating occurs, the procedure originally developed by Rutherford and Hutchings can be used 1,7,8-11. A series of tests were performed with different cycle number, and then the formation of the crater was caused by the contact-pressure at the center of the sphere with the sample. No difficulties were found to measure the crater in the TiN samples due the regular shape of the contour created in the pair substrate-film, as shown in Figure 5. The micrograph reveals a "ring" of considerable width at the outer edge of the crater. Differently, the samples of DLC showed a non perfect diameter of the crater, as shown in Figure 6. There were difficulties in defining the edges of craters for DLC as indicated by the diameters variations; moreover, the grooves in the edge interfere in the measurements of the inner craters diameters, also scuffing effect have occurred around the edge of the crater. This scuffing effect can cause difficulties in determining the real edge of the crater. When the crater with irregular shape is observed, the coating volume calculated is strongly affected, since the formulas of the volumes (4 and 5) are dependent on internal diameter (a) and the thickness ( $\mathrm{t}$ ). Apart from a slight fuzziness of the crater edge this micrograph allows for a fair measurement of the corresponding crater intersect diameter. Interesting points are raised by Gee et al. (2003) ${ }^{1}$. They reported the same factors observed here which affect the accuracy of measurements: the difficulty in resolving the edges of craters; the method of scar size measurements; the fact that non-perfect crater shapes are often seen in tests; and the theory for analyzing results may not be appropriate for all materials and test conditions.

Images from the alternative technique suggested here are presented in Figure 7. The volume from the profile of the crater has been calculated to the pair substrate-film. Thus, results obtained by profilometry were useful for comparison with the volumes calculated by conventional method.

Figure 8 shows the coefficient of friction during the ball cratering test. Friction and normal forces were captured by wear-acquisition and real-time analysis system. With the expectation of the tests on TiN, the average coefficient of friction (0.7) for the TiN-coated substrate is quite high, if 


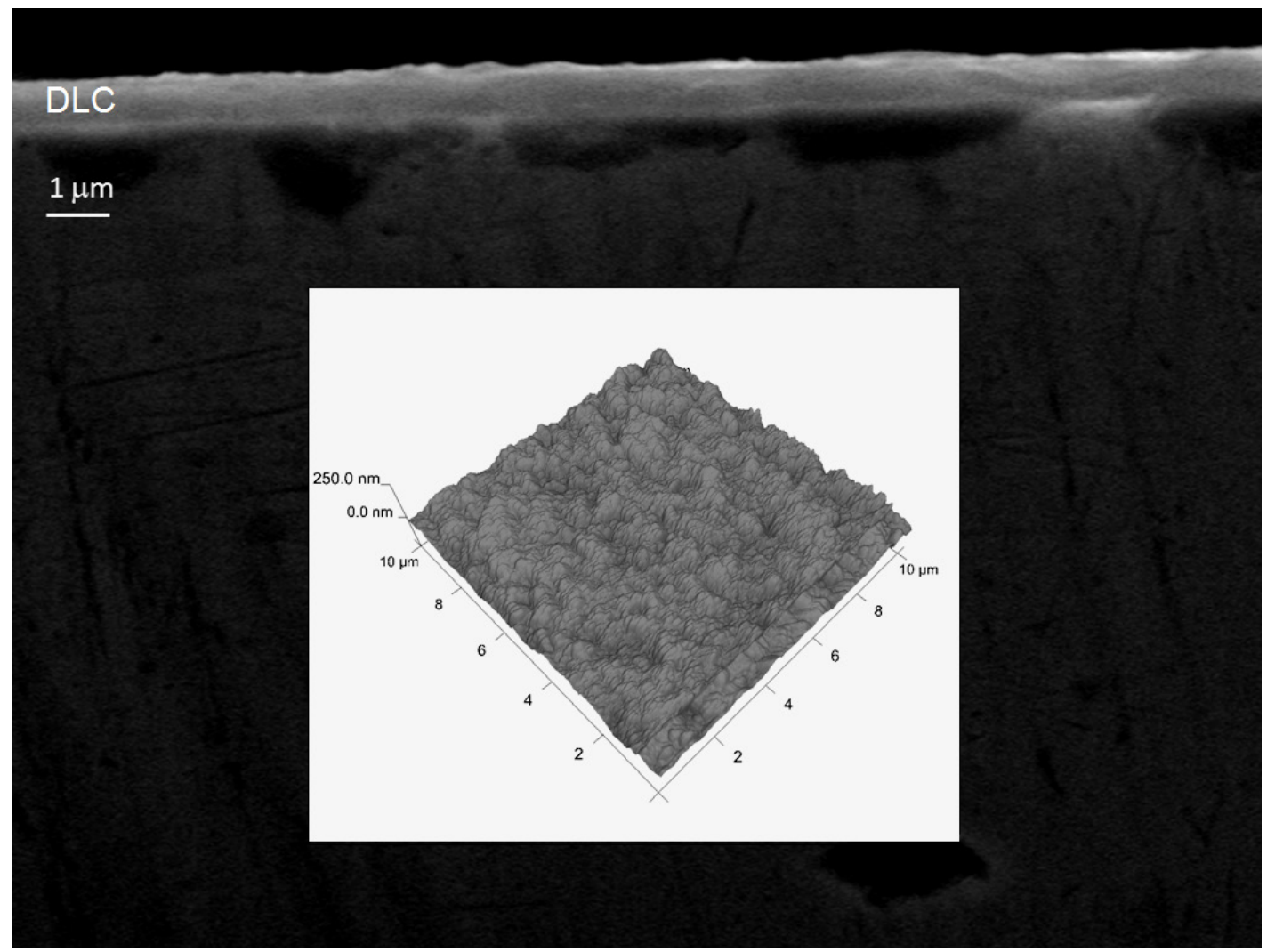

Figure 4. Cross-section view of the thickness of DLC coating by scanning electron microscopy and the morphology of the DLC coating by AFM (inside).

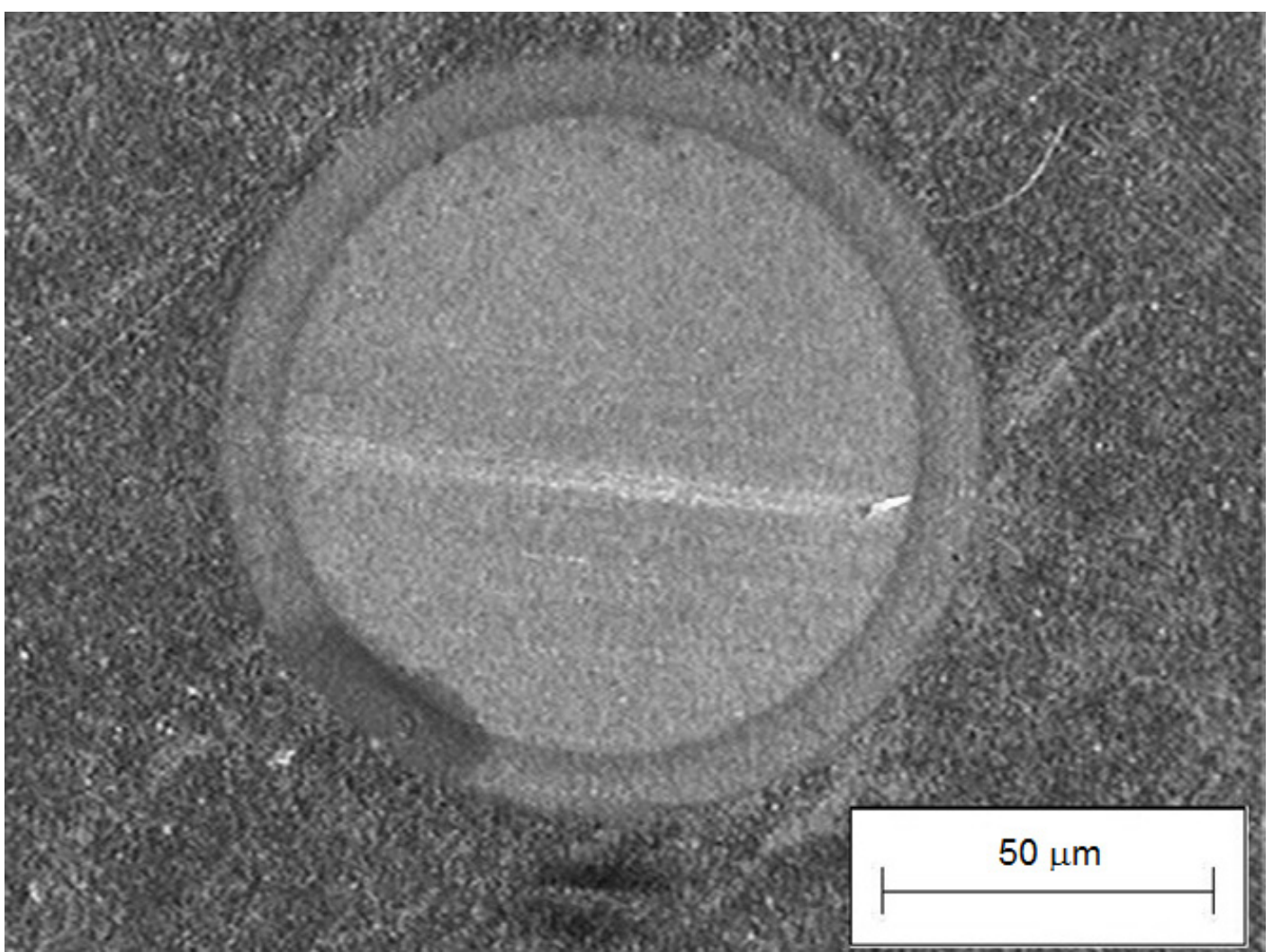

Figure 5. Crater produced in TiN-coated steel sample by optical microscopy. 


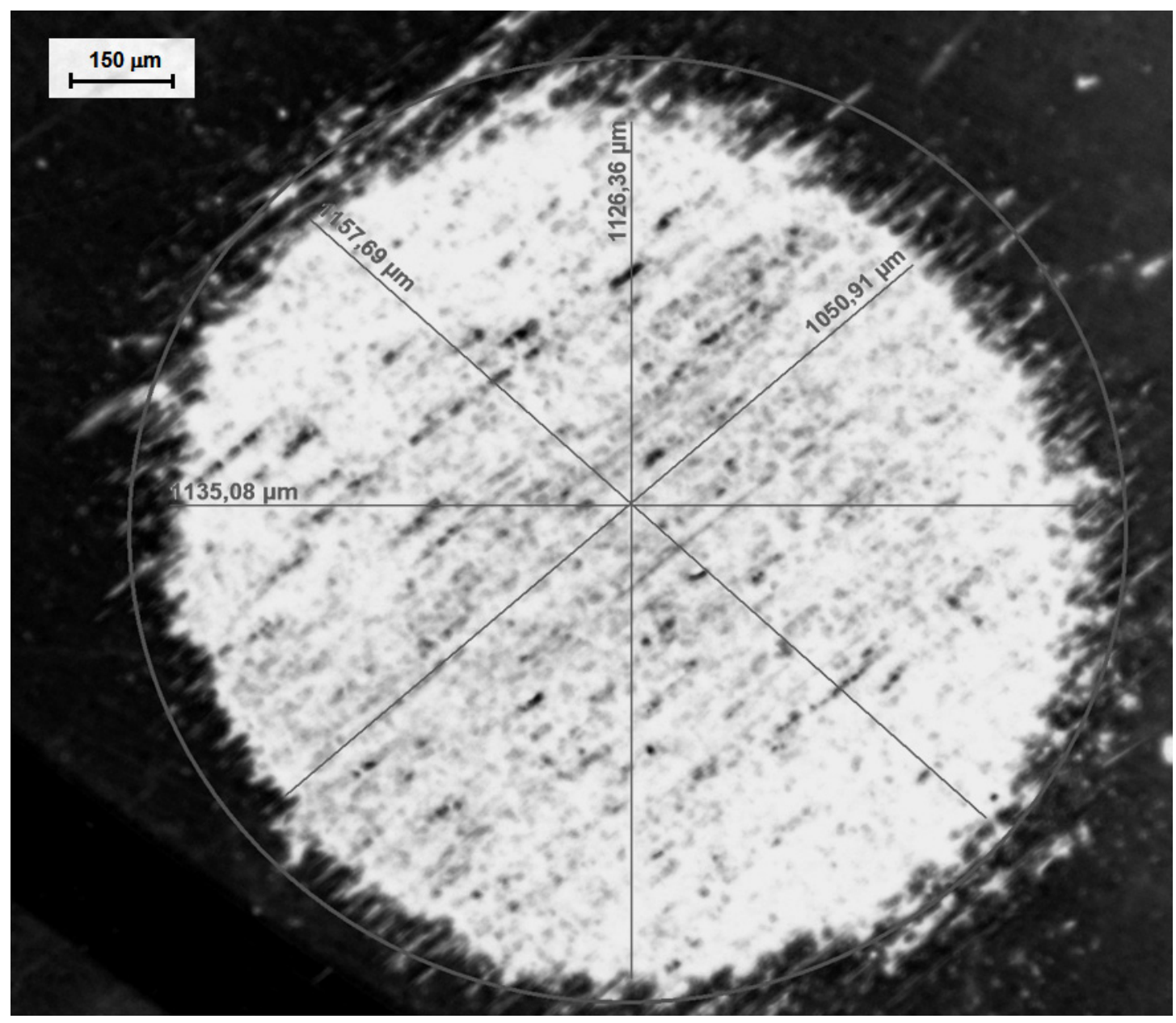

Figure 6. Crater produced in DLC-coated steel sample by optical microscopy. The crater edge has grooves in which became difficult the diameters measurements.

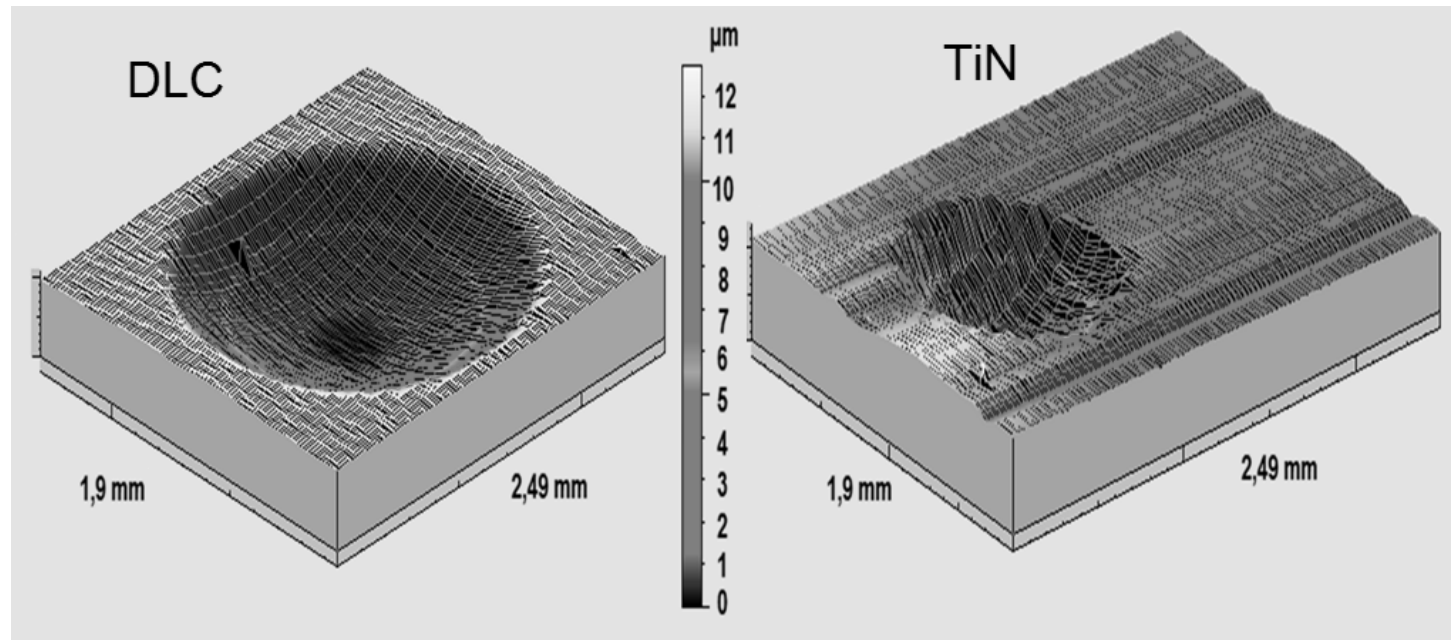

Figure 7. Crater profile of DLC and TiN by profilometry.

compared with the coefficient of friction (0.3) of DLC. Mechanical properties as hardness of DLC and Young modulus are related to the low coefficient of friction for DLC, however for TiN coating the non-uniform morphology, as observed in the AFM image on Figure 3, can influence the friction during the test.

From the slope of the linear fits to the data, as shown in Figure 9, this method provides a simple indication whether $\mathrm{k}_{\mathrm{c}}$ 


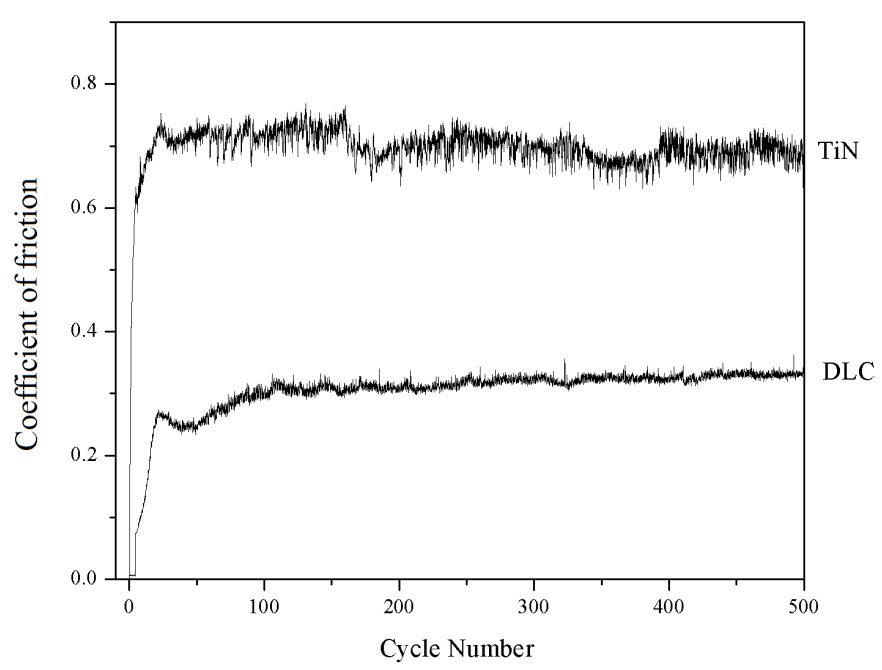

Figure 8. Coefficient of friction for TiN and DLC.

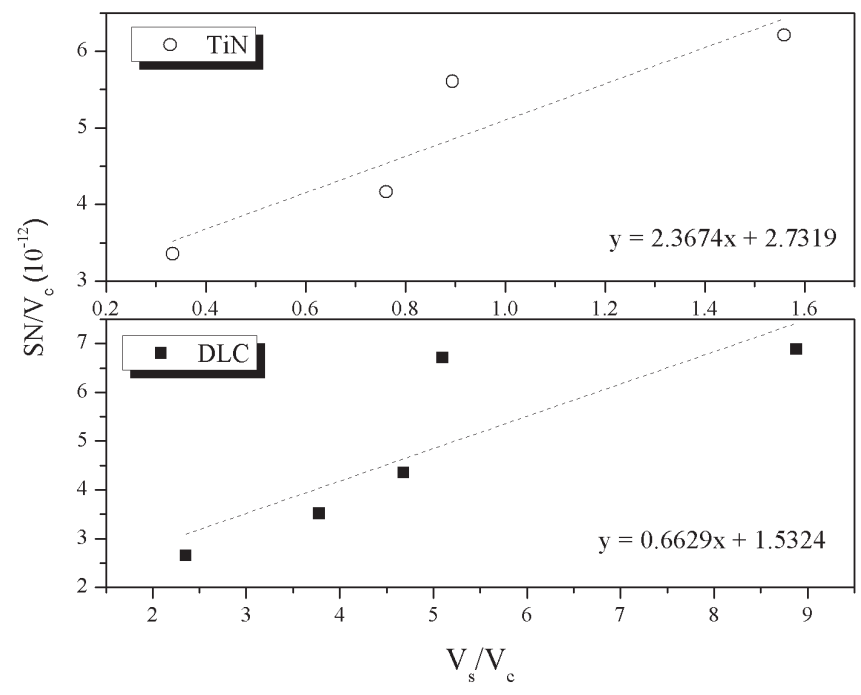

Figure 9. Plots of abrasion wear data obtained for TiN-coated M2 steel and DLC.

is greater or less than $\mathrm{k}_{\mathrm{s}}$. An advantage is its potential accuracy since the value of S.N is generally much more accurate than the volumes calculated from the measured wear scar dimensions. Separate wear scars were formed after varying numbers of ball rotations and have been measured by optical microscopy. For each scar at least five measurements of a and $b$ were made parallel and perpendicular to the abrasion direction to obtain mean values of $a$ and $b$.

The internal crater diameters and the external crater diameters for TiN and DLC were both measured as shown in Figure 10 and plotted against SN. There is a steady increase tendency in the size of internal and external TiN diameters, differently, a non-steady increase is observed for DLC.
Probably, the factors like thickness and wear resistance are responsible for the result of each coating.

The specific wear coefficient of the substrate $\left(\mathrm{k}_{\mathrm{s}}\right)$ and the coating $\left(\mathrm{k}_{\mathrm{c}}\right)$ by the four methods of data analyses plus profilometer are discussed based on the Figure 11. Wear coefficients using the volumes from profilometer have been compared with those obtained by the conventional method. The wear coefficients of TiN and DLC samples of all methods are consistent with the values reported in the literature $^{2}$. Interesting results for the DLC wear coefficients were calculated by Vc-At and DI, which show significant difference between $\mathrm{ks}$ and $\mathrm{kc}$, indicating that the wear of the coatings were lower than the substrate. Although, the wear 


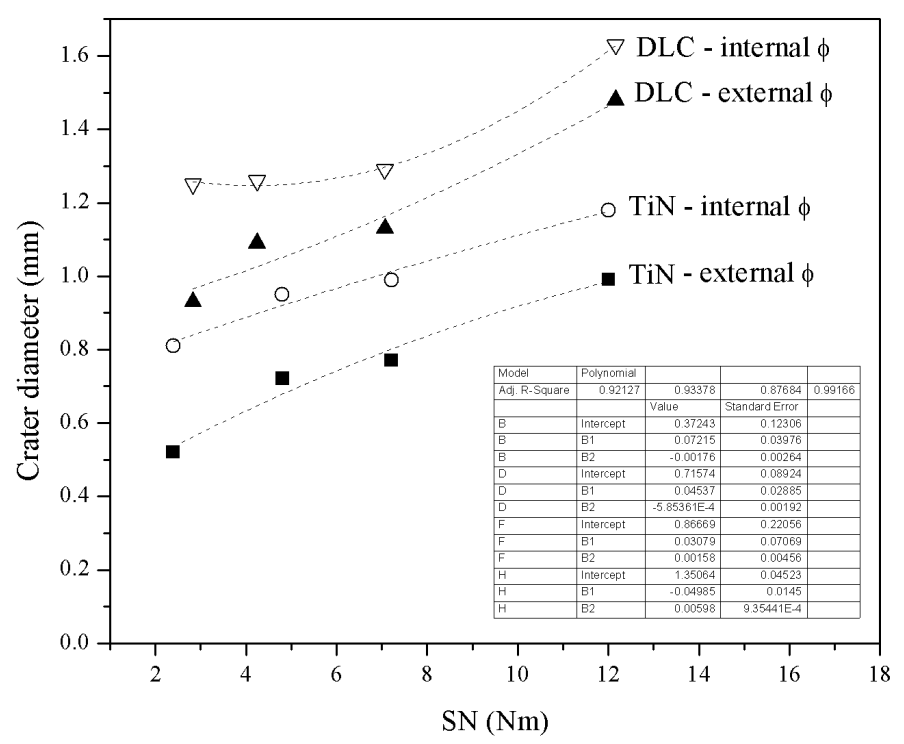

Figure 10. Experimental data obtained from ball-cratering tests on TiN and DLC coated sample with mean values of the internal and external crater diameters.
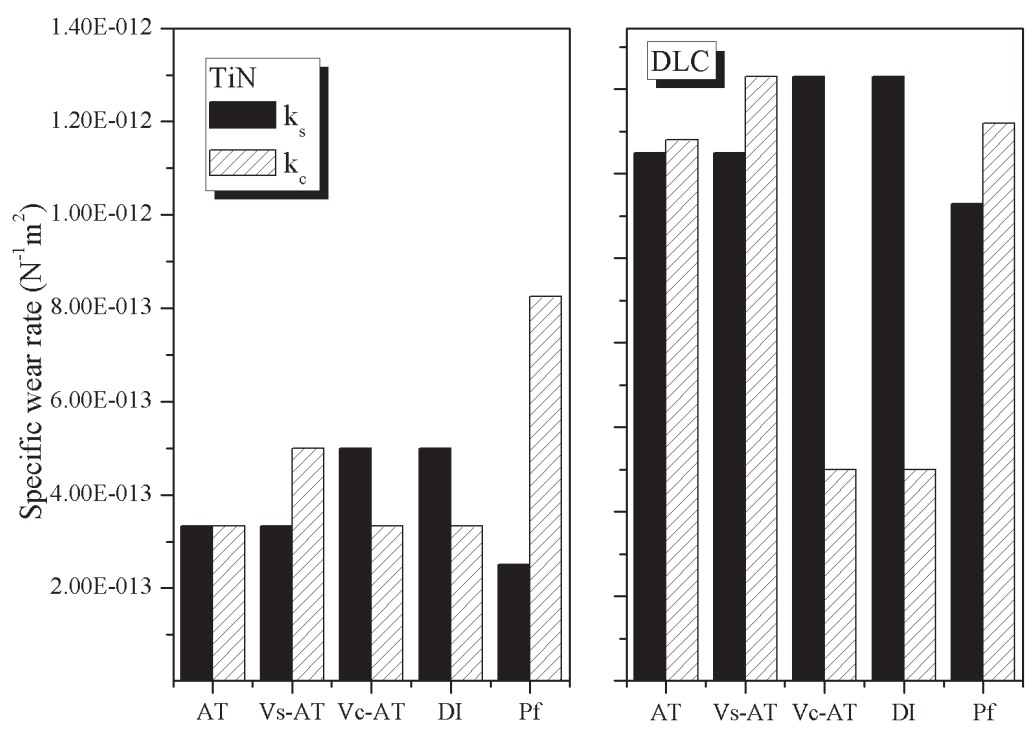

Figure 11. Evaluation of specific wear rates of substrate and coating, ks and kc, using four equations of data analyses methods (AT, Vs-AT, Vc-At and DI by conventional micrsocopy) compared with specific wear rates of ks and kc from the data obtained using profilometry (pf) technique.

results of specific wear rate are not with the same tendency, the coefficient of the substrate $\left(\mathrm{k}_{\mathrm{s}}\right)$ often is greater than the coating $\left(\mathrm{k}_{\mathrm{c}}\right)$. However, in the profilometer method $\mathrm{k}_{\mathrm{c}}$ was greater than $\mathrm{k}_{\mathrm{s}}$ for both coatings, probably due poor accuracy. Therefore, the use of profilometer to measure the volume of the crater needs to be better understood, while Vc-At and DI are the best analyses methods.

\section{Conclusions}

The titanium nitride coating is widely known in machining industries and has been successfully used to make a comparison with DLC which is a new technology. The roughness does not have influence significantly on the wear results of both coatings. The ball cratering test was evaluated to be appropriate method for calculating the 
specific wear rate, once the use of correct equation. The use of profilometer for analysis of the crater from ball cratering test proved to be non-applicable and consistent if compared with the conventional method, due the profilometer analysis cannot discriminate between the coating and the portion of the substrate. Therefore, conventional method can be applied to a variety of test and abrasive material. Although it is realized that the method for defining the boundary between the DLC coating and the substrate for the gray color changes needs to

\section{References}

1. Gee M, Gant A, Hutchings I, Bethke R, Schiffman K, Van Acker $\mathrm{K}$, et al. Progress towards standardisation of ball cratering. Wear. 2003; 255(1-6):1-13. http://dx.doi.org/10.1016/S00431648(03)00091-7.

2. Vanhulsel A, Velasco F, Jacobs R, Eersels L, Havermans D, Roberts E, et al. DLC solid lubricant coatings on ball bearings for space applications. Tribology International. 2007; 40(7):11861194. http://dx.doi.org/10.1016/j.triboint.2006.12.005.

3. Fildes J, Meyers S, Mulligan C and Kilaparti R. Evaluation of the wear and abrasion resistance of hard coatings by ball-onthree-disk test methods - A case study. Wear. 2013; 302(12):1040-1049. http://dx.doi.org/10.1016/j.wear.2012.11.018.

4. Mello J, Binder R, Demas N and Polycarpou A. Effect of the actual environment present in hermetic compressors on the tribological behavior of a Si-rich multifunctional DLC coating. Wear. 2009; 267(5):907-915. http://dx.doi.org/10.1016/j. wear.2008.12.070.

5. Suzuki M, Saito T and Tanaka A. Tribological properties of DLC films against different steels. Wear. 2013; 304(1-2):83-87. http://dx.doi.org/10.1016/j.wear.2013.03.046.

6. Zeiler E, Klaffke D, Hiltner K, Grögler T, Rosiwal S and Singer R. Tribological performance of mechanically lapped chemical vapor deposited diamond coatings. Surface and Coatings Technology. 1999; 116-119:599-608. http://dx.doi. org/10.1016/S0257-8972(99)00136-X.

7. Gee M. The use of PC scanners in micro-abrasion wear testing. Wear. 2005; 259(7):1448-1452. http://dx.doi.org/10.1016/j. wear.2005.02.090.

8. Gee M, Gant A, Hutchings I, Kusano Y, Schiffman K, Van Acker $\mathrm{K}$, et al. Results from an interlaboratory exercise to validate the micro-scale abrasion test. Wear. 2005; 259(1):27-35. http:// dx.doi.org/10.1016/j.wear.2005.02.092.

9. Gee M and Wicks M. Ball crater testing for the measurement of the unlubricated sliding wear of wear-resistant coatings. Surface and Coatings Technology. 2000; 133-134:376-382. http://dx.doi.org/10.1016/S0257-8972(00)00966-X. be better understood, it seems that the conventional method has the advantage on profilometer.

\section{Acknowledgments}

WMS would like to thank the help of André Bragança Carvalho França, Valéria Gomes, Dr. Claudinei José Oliveira, Dr. Gilmar Cordeiro da Silva and Dr. Pedro Paiva Brito.

10. Kusano Y, Acker K and Hutchings I. Methods of data analysis for the micro-scale abrasion test on coated substrates. Surface and Coatings Technology. 2004; 183(2):312-327. http://dx.doi. org/10.1016/j.surfcoat.2003.10.010.

11. Sabatini G, Ceschini L, Martini C, Williams J and Hutchings I. Improving sliding and abrasive wear behavior of cast A356 and wrought AA7075 aluminum alloys by plasma electrolytic oxidation. Materials \& Design. 2010; 31(2):816-828.

12. Leroy C, Schiffman K, Acker K and von Stebut J. Ball Cratering an efficient tool for 3 body microabrasion of coated systems. Surface and Coatings Technology. 2005; 200(1-4):153-156. http://dx.doi.org/10.1016/j.surfcoat.2005.02.076.

13. Chen H, Xu C, Zhou Q, Hutchings I, Shipway P and Liu J. Micro-scale abrasive wear behavior of HVOF sprayed and laserremelted conventional and nanostructured WC-Co coatings. Wear. 2005; 258(1):333-338. http://dx.doi.org/10.1016/j. wear.2004.09.044.

14. Rutherford $\mathrm{K}$ and Hutchings I. A micro-abrasive wear test, with particular application to coated systems. Surface and Coatings Technology. 1996; 79(1):231-239. http://dx.doi. org/10.1016/0257-8972(95)02461-1.

15. Silva WM, Carneiro JRG and Trava-Airoldi VJ. XPS, XRD and laser raman analysis of surface modified of 6150 steel substrates for the deposition of thick and adherent diamond-like carbon coatings. Materials Research. 2013; 16(3):603-608. http:// dx.doi.org/10.1590/S1516-14392013005000027.

16. Silva WM, Trava-Airoldi VJ and Chung YW. Surface modification of 6150 steel substrates for the deposition of thick and adherent diamond-like carbon coatings. Surface and Coatings Technology. 2011; 205(12):3703-3707. http://dx.doi. org/10.1016/j.surfcoat.2011.01.013.

17. Silva WM, Carneiro JR and Trava- Airoldi VJ. Effect of carbonitriding temperature process on the adhesion properties of diamond like-carbon coating deposited by PECVD on austenitic stainless steel. Diamond and Related Materials. 2014; 42:58-63. http://dx.doi.org/10.1016/j.diamond.2013.12.004. 